\title{
Diagnóstico precoce do câncer de pulmão
}

\author{
Klaus L. Irion \\ (E-mail: irion@irionradiologia.com.br)
}

\begin{abstract}
É preciso mudar o destino do pacientecom carcinoma brônquico. Existe al guma alternativa além do diagnóstico precoce e de não fumar?

N os moldes atual menterecomendados, o diagnóstico decarcinoma brônquico éfeito ao acaso ou pela identificação de al gum de seus sintomas clínicos (sempre tardio). Em conseqüência disto, um portador da doença tem cerca de $15 \%$ dechance deestar vivo cinco anos após o diagnós-
\end{abstract} tico. Os restantes $85 \%$ lutam pela sobrevivência, experimentam uma qualidade devida infernal, mas não chegam a viver esses escassos cinco anos. Isto não mais ocorre no câncer de próstata, de mama ou colo-retal. Nos dias de hoje, estes três cânceres agrupados matam menos que o câncer de pulmão isoladamente. Também nos dias dehoje o diagnóstico destas três neoplasias éfeito por técnicas que buscam identificá-las precocemente, ainda em fase subclínica. A o contrário, a busca pelo diagnóstico precoce do câncer de pulmão não é recomendada, em função de três famosos estudos da década de 70, que concluíram que rastreamento com radiograma de tórax, associado ou não à citologia deescarro, não modificava a mortal idade dos pacientes com carcinoma brônquico.

Depois da introdução da tomografia computadorizada helicoidal (TCH), poucos anos atrás, vários importantes centros de diagnóstico por imagem, inclusive al guns daqueles envolvidos nos três estudos referidos anteriormente, passaram a avaliar o emprego da TCH como uma al ternativa para modificar este quadro de absoluta desesperança no que se refere ao diagnóstico e tratamento do carcinoma brônquico. O Projeto Internacional de Ação no Câncer Precoce de Pulmão ("International Early Lung Cancer Action Project" - I-ELCAP) éum dos mais importantes esérios projetos quevêm sendo desenvolvidos para tentar reverter esta atitude contemplativa de esperar que o acaso ou alguma das manifestações clínicas diagnostiquecarcinoma brônquico ainda em fasedetratamento com vistas à cura.

Já está estabel ecido que a TCH de baixa dose é muito superior ao radiograma de tórax na detecção de nódulo pulmonar, em que mais de $50 \%$ dos nódulos menores que $2 \mathrm{~cm}$ deixam de ser identificados. N estes novos projetos, realizados pela Cornell University, Mayo Clinic e outros importantes centros de referência, estão sendo utilizadas TCH ecitologia de escarro. Associadas, permitem modificar completamente a proporção entre doença diagnosticada em fase de tratamento cirúrgico e doença diagnosticada em estágio avançado, em que o tratamento é, em geral, apenas paliativo. N os pacientes desses estudos, $63 \%$ dos carcinomas brônquicos detectados encontram-se em estágio I e 83\% encontram-se em estágio IIA ou menor. Isto significa que todos eles teriam chance de se submeter à cirurgia potencialmente curativa. Se considerados verdadeiros os conhecimentos atuais sobre carcinoma brônquico eestadiamento TN M, éóbvio queocorrerá uma mudança na sobrevida em cinco anos, passando dos atuais $15 \%$ para mais de $50 \%$, talvez até mesmo mais de $70 \%$.

O que acontecerá com a mortalidade? Ainda não se sabe ao certo. Afirma-se que sobrevida não é importante para avaliar eficácia detécnica de rastreamento equemortalidade é o parâmetro ideal para esta finalidade. Claudia Henschke e outros pesquisadores do I-ELCAP afirmam que, para utilizar o parâmetro mortalidade, o tempo de seguimento do grupo controle e do grupo submetido ao rastreamento teria que ser muito maior que o geralmente utilizado para medir a sobrevida. A o reavaliar os três grandes estudos de rastreamento do carcinoma brônquico da década de 70, verificaram quea projeção das linhas detendência da mortalidade do grupo controle e do grupo rastreado por um período de tempo maior mostra uma diferença significativa, sugerindo menor mortalidade nos pacientes submetidos ao rastreamento. Esta observação éimportante sob dois aspectos principais: 1 - é possível que não esteja correta a idéia de que rastreamento de carcinoma brônquico por raios-X de tórax e citologia de escarro não modifiquea mortalidade; 2 - seria correto esperar pelo menos mais dez ou quinze anos antes de se recomendar o rastreamento por $\mathrm{TCH}$ e citologia, até que os efeitos do rastreamento pudessem ser real mente medidos pela mortal idade, sabendo-se que os efeitos sobre a sobrevida indicam eficácia?

Mesmo que, se por milagre, todas as pessoas parassem hoje de fumar, durante os próximos vinte anos ainda teríamos uma multidão morrendo de câncer de pulmão. Além das campanhas contra o tabagismo, alguma coisa 
tem que ser feita. Prova disto éo recente estudo apresentado pela Mayo Clinic, em que num grupo de 520 pacientes tabagistas ou ex-tabagistas foram detectados 40 cânceres de pulmão. Destes, 40\% eram ex-fumantes, ou seja, haviam parado de fumar há mais de dez anos.

De acordo com os dados apresentados pel o grupo do I-ELCAP, só nos Estados Unidos, aproximadamente 170 mil pessoas morrem a cada ano de câncer de pulmão. Em termos mundiais, estima-se quemais um milhão denovos casos de carcinoma brônquico tenham sido detectados só no ano de 1990. Assim sendo, aquel es que propõem quese espere pelos resultados conclusivos sobreredução da mortal idade, devem ter consciência e responsabilidade sobre o número de mortes precoces que poderiam vir a ser evitadas se houvesse uma recomendação imediata para a busca pelo diagnóstico precoce do carcinoma brônquico, com osúni cos recursos atualmentedisponíveis. A resposta para estas questões só virá daqui a muitos anos, provavelmente com os resultados de um estudo queestará sendo iniciado dentro de poucos meses nos Estados Unidos, multicêntri$\mathrm{co}$, randomizado, abrangendo 50 mil norte-americanos, com repetição anual.

Há também que se considerar a possi bilidade de que o rastreamento levaria a diagnóstico excessivo, com identificação de carcinomas que eventualmente nunca se manifestariam clinicamente, nem seriam responsáveis pela morte do paciente. Seriam detectados mais cânceres pequenos, porém sem alteração no número de cânceres em estágio mais avançado. Isto poderia levar a uma mel horia na sobrevida, mas não reduziria a mortalidade. A o contrário, intercorrências do tratamento poderiam atémesmo aumentar a mortalidade. Esta preocupação pode até ser válida para outras neoplasias, mas no caso do carcinoma brônquico, responsável por mais de um milhão de mortes por ano em todo o mundo, o que temos que resolver primeiro, eque já está provado, éa fal ta de diagnóstico quando ainda se possa oferecer uma possi bilidade terapêutica eficaz. Não parece lógico deixar que especulações a respeito desta eventual e remota possibilidade impeçam ou retardem, à custa demil hões de vidas, a indicação da única alternativa que aparentemente possa vir a resolver um problema real, presente, desta magnitude.

Em relação ao custo, al guns dados devem ser suficientes para justificar a viabilidade desta ação: a) o SUS paga R\$136,40 por uma tomografia computadorizada detórax, ou seja, aproximadamente o que um fumante gasta em cigarros (dos mais baratos) a cada três meses para fumar uma carteira por dia. Isto representa que, a cada ano, o fumante deveria gastar só $25 \%$ do que despende para destruir sua saúde, numa tentativa deminimizar uma desuas complicações tardias, ou seja, uma pequena parte do imposto já atual mente embutido no seu preço; b) conforme os dados apresentados por $\mathrm{H}$ enschke, o custo com rastreamento por TCH detórax, para garantir a sobrevida emcinco anos de um paciente com carcinoma brônquico, é dez vezes menor que o gasto para cada vida salva com o rastreamento por mamografia.

Porém, alguns fatos contrários à imediata utilização do rastreamento do carcinoma brônquico têm que ser solucionados antes que a técnica seja oferecida aos fumantes pesados. Ainda não há uma preparação adequada da maioria dos radiologistas, nem dos clínicos ecirurgiões, quedevem mudar sua mentalidade frente ao nódulo pulmonar solitário. Um treinamento específico intenso é necessário antes que o radiologista passe a efetuar TCH com esta finalidade. As equipes de rastreamento devem ser multidisciplinares. No nosso entender, compostas por radiologistas, pneumologistas, cirurgiões torácicos, citologistas, anatomopatologistas, psiquiatras, bioestatísticos, entreoutros. Cada equipe deve estar afinada em termos de indicações de conduta. É preciso estar consciente de que a imensa maioria dos nódulos pulmonares detectados corresponde a lesão benigna, sem relevância clínica ou diagnóstica. Estamos falando que mais de $95 \%$ são nódulos benignos. É preciso segurar nosso ímpeto intervencionista que nos le varia a cometer inúmeras iatrogenias e certamente contribuindo para uma falência inadequada, indevida, desta promissora ferramenta no diagnóstico precoce do carcinoma brônquico. A conduta frente ao nódulo pulmonar identificado no rastreamento populacional deve ser padroniza$\mathrm{da}$, seguindo o que preconizam os grupos que compõem o I-ELCAP. N ossos primeiros passos neste sentido já foram dados. Juntamentecomo Colégio Brasileiro de Radiologia ea SociedadeBrasileira de Pneumologia eTisiologia, criamos um braço brasileiro do I-ELCAP. Este está em fase de organização e estará, em breve, à disposição de todos os interessados em participar. O objetivo é iniciar no passo certo, visando a uma padronização ea um controle de qualidade desde a implantação do rastreamento.

É preciso lembrar, também, que provavelmente não estejamos propriamente falando de rastreamento populacional; afinal, o tabagismo já éum sintoma da doença. São raras as doenças quetêm um sintoma tão objetivo em quase $100 \%$ dos casos. 